\title{
aproveitar propriedades para construir vias de comunicação: o caso das fazendas bebedouro (brasil) e a luisiana (colômbia), 1870-1900*
}

\section{to take advantage of properties to build roads of communications: the case of the farms bebedouro (brazil) and a luisiana (colombia),}

1870-1900

\author{
Clara Inés Carreño Tarazona $\star \star$ \\ Faculdade de Ciências Jurídicas e Sociais, Universidade de Boyacá, Tunja, Boyacá, Colômbia
}

\section{ReSUmo}

Este artigo procura analisar através da comparação as estratégias (vínculos políticos e redes sociais) empregadas pelos fazendeiros e proprietários no Brasil e na Colômbia, assim como a utilização da fazenda como suporte e os capitais fornecidos pela semeadura de produtos agrícolas para garantir o aproveitamento em vias de comunicação. Três temas apresentam-se importantes para a presente análise. Primeiro, a consolidação das fazendas com a criação de associações e laços entre família e parceiros a partir de alianças e cooperação. Segundo, a organização de mercados locais e redes comerciais suportadas pelas fazendas com o fim de ingressar nos mercados regionais. Terceiro, a posse sobre a fazenda deixa ver o fortalecimento

\begin{abstract}
This article seeks to analyze the strategies (political ties and social networks) employed by socioeconomic groups in Brazil and Colombia, as well as the use of the farm as support and the capital provided by the sowing of agricultural products to guarantee investment in roads of communication. Three themes are important for the present analysis. First, the consolidation of farms with the creation of associations and ties between family and friends from alliances and cooperation. Second, the organization of local markets and commercial networks supported by farms in order to enter regional markets. Third, the pose on the farm reveals the economic strengthening of the groups, as a condition to promote and
\end{abstract}

* A autora agradece o apoio recebido dos professores José Luís Bendicho Beired e Lélio Luiz de Oliveira ao longo da pesquisa de doutorado, que originou o presente artigo, e à Faculdade de Ciências e Letras da Universidade Estadual Paulista o financiamento (Bolsa de Doutorado PAEDEX-UNESP/AUIP).

Submetido: 13 de janeiro de 2017; aceito: 28 de setembro de 2017.

$\star \star$ Docente-investigadora da Faculdade de Ciências Jurídicas e Sociais da Universidade de Boyacá, Tunja (Colômbia). Doutora em História pela Faculdade de Ciências e Letras da Universidade Estadual Paulista. Mestre em História pela Universidade Industrial de Santander, Bucaramanga (Colômbia).E-mail: clarainesct@gmail.com 
econômico dos grupos, como condição para promover e obter beneficio sobre as vias de comunicação. As fontes usadas são principalmente livros notariais, escrituras, inventários, doações e divisões de fazendas.

Palavras-chave: Vias de comunicação. Fazendas. Famílias. Brasil. Colômbia. benefit from the means of communication. The sources used are mainly notary books, deeds, inventories, donations and divisions of farms.

Keywords: Roads of communications. Farms. Families. Brazil. Colombia.

\section{Introdução}

Em 1879 José Bernardes da Costa Junqueira morreu na sua Fazenda Bebedouro. Dentro dos bens havidos, deixou para sua esposa Inácia Cândida de Andrade e seus filhos uma herança representada em sua maioria de terras, escravos, animais e cultivos.

A fazenda que limitava com terrenos e outras fazendas de propriedade da mesma família fazia parte dos inventários, divisões e doações muito comuns na região de Franca, ao norte do estado de São Paulo, entre os anos 1870 e 1900.A divisão da fazenda foi o resultado da compra da herança por um único membro da família, o qual terminou acumulando uma importante quantidade de terras de diferentes extensões, aproveitando sua localização estratégica no cruzamento de vários rios e caminhos para o transporte de gado; e, finalizando o século XIX, converteu-se no eixo central na construção da linha ferroviária da Companhia Mogiana de Estradas de Ferro.

Em data próxima, embora não sobre o mesmo espaço, o viajante Isidoro Laverde Amaya, em seu percurso atéVenezuela, arribou a Bucaramanga, descrevendo-a como uns dos vilarejos mais comerciais do Estado de Santander, assentado ao Nordeste da Colômbia. Povoado de inúmeros habitantes, com um grande grupo de comerciantes estrangeiros, particularmente alemães, mas carente de água e com construções pouco notáveis, dito povoado foi o centro de negócios da companhia comercial nomeada Reyes González \& Hermanos. A companhia se constituiu no ano 1882 pela associação de três irmãos, Reyes, Eleuterio e Florentino González, os que acumularam o capital considerável para comprar a Fazenda A Luisiana.

As oportunidades que outorgaram as relações entre os três irmãos e sócios, os laços familiares e a proximidade com o poder político permi- 
tiram estabelecer uma rede social que lhes ajudou a se fortalecerem na região, tanto na parte rural quanto na urbana.

Os casos analisados apresentam o contexto típico de dois espaços que coexistiram entre o final do século XIX e o alvorecer do XX, acentuado pela interação entre a vida urbana e os hábitos próprios das áreas rurais, destacando-se a fazenda como a unidade econômico-social, utilizada como garantia para ampliar os mercados regionais.

Durante os primeiros anos do século XX, dentro das atividades mais importantes para os fazendeiros destacam-se o ingresso no comércio através da criação de bancos e estabelecimentos comerciais e de serviços, a modernização da cidade a partir de investimentos, a participação política e a construção de caminhos e estradas de ferro.

$\mathrm{Na}$ Colômbia, embora não se tornara forte a ideia da ferrovia, a produção de bens agrícolas representou importantes vantagens em termos técnicos e econômicos, próximo à produção de outros gêneros da terra e à troca da propriedade-raiz. O capital comercial acumulado com o negócio do quinino, ouro, índigo e tabaco (Machado, 2001, p. 77) e a compra e venda de terras facilitaram os recursos necessários para a conformação das fazendas, e mais adiante possibilitou a associação e fundação de casas comerciais. Isso provocou o aumento da exportação de produtos da terra e a introdução e venda de mercadorias estrangeiras (Carreño, 2009, p. 228). O estabelecimento de pequenas indústrias (Botero, 2003, cap. II-III), a compra e venda de prédios urbanos, a participação nos remates da renda de aguardente e as atividades complementares foram desenvolvidas no interior das fazendas, com o apoio da produção e exportação de café, a cana-de-açúcar, a cria de gado, as plantações de cacau e tabaco, a exploração do quinino, os mineiros e os investimentos em maquinaria.

No Brasil, o fortalecimento da elite a partir da diversificação da agricultura e das atividades econômicas enfocadas na exportação e no mercado interno não dissolveu a pequena produção rural (Oliveira, 2006, p. 113-114, 141-143). A função das estradas de ferro foi determinante para o fortalecimento dos fazendeiros, os quais, além de se engajarem na produção de café, também foram distribuidores de outros produtos cultivados nas suas propriedades e de outras atividades complementares, sendo importante, por exemplo, o crédito (Tosi; Faleiros, 2011), a escravidão, o trabalho familiar (Abrahão, 2010) e a imigração. 
Da mesma forma vincularam-se à economia do café, do açúcar, da aguardente, do algodão, da borracha, dos minerais, do couro, dos teares, do sal, do arroz, do milho, da mandioca, do gado, das mulas, dos cavalos, dos perus, das galinhas, das cabras e dos porcos (Oliveira, 2006), a partir da acumulação de capital e da coexistência de grandes latifúndios com pequenas propriedades de terra (Faleiros, 2002, p. 4). Ao mesmo tempo em que a cafeicultura atingiu a riqueza, transformando-a, produziu alternativas diferentes no uso de escravos; foi a causante de fazer parcerias com empresas ferroviárias, bancos e casas comerciais. Estimulou a compra e venda de propriedades rurais e urbanas e as reformas nas cidades e nos mobiliários (Faleiros, 2002, p. 28).

Enquanto isso, a fazenda torna-se o ponto de convergência de atores e redes sociais que mantinham, simulando um modelo de ligações dinâmicas (Florescano, 1999; Van Young, 1989; Chevalier, 1999; Bauer, 2009; Mörner, 1999, 1973; Florescano, 1975), em que as atividades agrícolas coexistiram com as regulamentações governamentais e o ambiente familiar (Zúñiga, 2000, p 58). Sua posição tradicional e próxima conectou o parentesco, a vizinhança e as práticas do tipo de compadrio, com a dinâmica de circuitos comerciais (Machuca, 2011-2012, p. 90), oferecendo muitas oportunidades para ir até ela, em caso de falhar uma instituição ou pessoa.

Internamente o Brasil e a Colômbia dependiam da existência de mercados locais e dos fluxos comerciais ligados a empresas e fazendas. Seu desenvolvimento foi influenciado pelas condições geográficas, pelas dificuldades nos meios de comunicação e pela presença de redes de produção controladas. No ambiente comum das fazendas, incluem-se as várias atividades agrícolas e industriais, as descrições de áreas comuns para o cultivo e os assentamentos, as extensões e características da terra, a população e as formas cotidianas de transporte.

Entre os anos de 1870 a 1900, no Brasil e na Colômbia foi consolidado um período assinalado pela acumulação de capital através do comércio de commodities, bem como pelo crescimento da produção e exportação de café (Bulmer-Thomas, 1996, p. 162-163). Embora essa produção no Brasil e na Colômbia ascendeu de forma muito diferente, os dois países conheceram um período chamado de desenvolvimento primário-exportador, que concorda integralmente com a chamada primeira globalização (Bértola; Ocampo, 2013), período em que a Amé- 
rica Latina enfocou suas políticas econômicas nos novos cenários internacionais, aumentando a dependência das exportações de produtos primários.

Os mencionados anos servem como ponto de referência para analisar as conexões e redes que surgiram nos dois países e em duas áreas específicas em que a fazenda se expandiu durante o mesmo período, destacando-se a propriedade como uma garantia para se aventurar em negócios comerciais, e também para o uso de meios de comunicação.

Tomando como referência esse espaço de tempo e utilizando como metodologia a análise comparativa, é de notar que o interesse em terras da fazenda pôde produzir efeitos muito diferentes devido a circunstâncias históricas, resultante das práticas do desempenho político-econômico e das práticas sociais nos dois países.

Apesar de projetar desafios estimulados pela prudência, como diz Maria Ligia Coelho Prado (2005, p. 15), a regra fundamental da análise comparativa entre os dois países vai depender do objeto de estudo. Nesse caso, estuda-se a fazenda em duas áreas geográficas e dois contextos sociais diversos, para reconstruir as relações entre dois grupos de diferentes famílias com distintas escolhas, mas também distinguidos pelo interesse para participar na formação de capitais utilizados para assegurar as rotas comerciais.

E, na mesma linha, a análise comparativa permite "descrever as curvas da evolução, encontrar semelhanças e diferenças, e tanto quanto possível explicar à luz da aproximação entre eles [...], assim como a importância de estudar duas sociedades paralelas e contemporâneas vizinhas, sociedades sincrônicas perto uma das outras no espaço". Além disso, a leitura da crítica das bibliografias deve conduzir à formulação de perguntas e novos problemas, permitindo as "influências" exercidas por uma sociedade sobre a vizinha, assim como o mesmo Marc Bloch propôs (apud Coelho Prado, 2005, p. 17-18). Além disso, segundo Chevalier,

a comparação ajuda para que os fenômenos e problemas históricos não acabem sendo, em cada país, únicos no seu gênero. Colocar em paralelo a fazenda com outras formas de propriedade ou outras categorias sociais de outros países não significa que os fenômenos se repetem exatamente ou instituições e costumes fiquem inseridos em um meio diferente, sem mudanças profundas. (Chevalier, 1999, p. 65) 
Do mesmo modo, usa-se a metodologia da análise teórico-metodológica fornecida pela micro-história (Man, 2013, p. 167-173). Segundo Jacques Revel (apud Levi, 2000, p. 7-37), o tipo de método da microanálise, como um sistema de múltiplas interações e resultado das forças plurais, ajuda a limitar o campo de visão das experiências próprias deste grupo de personagens cujo comportamento é atravessado em vários contextos, espaços e tempos, a partir da utilização de estratégias, solidariedade, parceria e itinerários familiares.

A seleção da fazenda, sob a lupa da análise microanalítica (Moutoukias, 2002, p. 69-103), permite analisar de maneira particular a natureza geral dela no final do século XIX, assim como as questões relacionadas com as mudanças na extensão da propriedade, a relação proprietário-comerciante (Sánchez Santiró, 2000, p. 924), suas negociações e estratégias no contexto comercial e familiar do período, a distribuição dela entre os herdeiros, a venda de terras aquinhoadas das áreas mais produtivas, as estratégias dos proprietários para dispor da propriedade, como um meio para garantir a sua entrada em outras atividades diretamente relacionadas com as vias de comunicação.

O conjunto de fontes similares produzido nos dois países ajudará a identificar e esboçar uma interpretação diferente e um modelo alternativo para as fontes documentais do final do século XIX e início do $\mathrm{XX}^{1}$. Comparar a história e a historiografia significará uma vantagem para fazer perguntas, para renovar ideias sobre o desenvolvimento de ambos os países, cujos fatos permitam fornecer elementos para fazer comparações. Ao confrontar dois contextos diferentes, são evidentes os problemas, situações e costumes próprios de cada um dos países, para afrontar os novos desafios trazidos com o modernismo e o desenvolvimento da economia mundial. As economias internas de cada país são pouco examinadas, tendo em conta as numerosas pesquisas sobre o domínio econômico do café na exportação. Daí a importância de encontrar vários objetos de estudo que mostrem as características e as expe-

\footnotetext{
O corpus documental para a presente pesquisa se compõe de livros cartoriais, registros de nascimento, de batismo, de matrimônio; doações, inventários, testamentos post mortem, jornais, hipotecas, almanaques e constituição de empresas comerciais. Acervos localizados no Arquivo Histórico Regional da Universidad Industrial de Santander da cidade de Bucaramanga (Santander-Colômbia) e no Arquivo Histórico Municipal Capitão Hypólito Antônio Pinheiro de Franca (São Paulo-Brasil).
} 
riências próprias de cada um deles. Pesquisas locais mostram as muitas opções que dependem de fontes, tais como inventários e livros notariais, cujo conteúdo é quase nunca usado para analisar os diferentes elementos que conviveram dentro das fazendas (Tosi; Faleiros, 2011, p. 418- 419).

\section{As fazendas: sócios e laços de família}

\subsection{Divisão entre a família: a Fazenda Bebedouro}

Com a morte do major José Bernardes da Costa Junqueira, em 1879, iniciou-se a divisão da Fazenda Bebedouro ${ }^{2}$, localizada na região de Franca e local de residência da viúva Inácia Cândida de Andrade e de seus herdeiros, sete filhas e dois filhos.

Em 1881, foi determinado que a Fazenda Bebedouro, formada por extensões de terra, campos e culturas, fosse delimitada em dois lados. $\mathrm{O}$ primeiro limite com propriedades de Severo Joaquim da Costa, Emirena Francisca da Costa, José Garcia Duarte, José Esteves de Andrade, Isaac Villela de Andrade e Joaquim Bernardes de Andrade. O segundo limite com propriedades de Antônio Flavio de Castro, dos herdeiros de Antônio Joaquim de Mello, de José García Duarte, de Quirino Barbosa Sandoval, de Martiniano Francisco da Costa, de Teolinda Zemila de Andrade, da Fazenda Monte Bello e de Zeferino José do Nascimento. Esses nomes são muito importantes para analisar como as propriedades foram distribuídas entre as famílias, ao longo do século XIX. Esses personagens foram envolvidos em compras e vendas sucessivas dentro do mesmo círculo de parentesco, mostrando a acumulação de doações, heranças e trocas recíprocas.

A Fazenda Bebedouro estendia-se a partir de quatro pontos referenciais. Desde Franca até o rio Sapucaí e desde Restinga até o rio de

2 "Em 1890 a Delegacia da polícia da Franca criou uma nova ordem de blocos ou quadras, nomeando, como encarregado da quadra n. 14 ou Palmital, Martiniano Francisco da Costa. Esta quadra fazia parte da divisória de Antônio Flausino de Castro, das Macaúbas, descendo até o rio Sapucaí e deste até a divisória do Ribeirão dos Bagres até os limites de Bebedouro de Joaquim Bernardes de Andrade (1890). Juizado de Paz da Franca", documentos, s.f., Arquivo Histórico Municipal, Franca, Brasil. 
Santa Bárbara, na divisa com o Patrocínio de Sapucaí. Foi uma área com uma extensão significativa de terras, fornecendo uma ligação entre Franca e a região de Batatais. Essas circunstâncias condicionaram não só à produção agrícola, também permitiu a incorporação nas suas propriedades de uma rede da Companhia Ferroviária Mogiana. As estações de Boa Sorte, Mandiú e Restinga transformaram-se, ao lado das Macaúbas (Franco, 1902, p. 103), nos pontos de conexão mais usados desde o final do século XIX, tornando fáceis as transações comerciais entre as duas cidades.

Embora a distribuição de terras fosse justa, alguns daqueles que receberam a herança venderam as ditas terras às suas famílias. A distribuição da herança fragmentou e formou novas fazendas, também mudou a estrutura hierárquica da família, para dar centralidade às redes formadas por José Garcia Duarte e Martiniano Francisco da Costa. O primeiro, nascido em 1824, em São Miguel de Cajuru (MG), foi um renomado dono de plantações de café, comerciante, proprietário e promotor de obras civis, sociais e culturais em Franca. Ele também serviu como vereador, presidente, vice-presidente da Câmara Municipal e chefe da Polícia na década de 1880 (Naldi, 1992, p. 72-73).

Parte da riqueza de José Garcia Duarte correspondeu à herança da sua esposa Ana Cândida Junqueira, que morreu em 1872, representada principalmente na Fazenda Bebedouro ${ }^{3}$.Assim, ele consegue acrescentar mais terras, além daquelas ganhadas de doações anteriores e perto da mesma Fazenda Bebedouro e do rio Sapucaí, onde ele tinha construído uma ponte alugada à administração provincial. Assim, Garcia Duarte aumentou a sua herança, começando a aparecer como um fazendeiro proeminente, criador de gado e produtor de açúcar e algodão (Naldi, 1992, p. 79-80). O casal teve duas filhas, Inácia, casada com Antônio Flavio Martins Ferreira, colega político de Garcia Duarte no Partido Católico (Camelucci, 2008, s.p.), e Firmina, casada com Luciano Vieira Santiago, natural de Santa Rita de Cássia (MG) (Naldi, 1992, p. 79; Camelucci, 2008).

Para facilitar os seus negócios e adquirir terras com acesso às principais rotas comerciais, Garcia trocou com suas filhas e seus genros

3 Inventário, Cartório do 2o Ofício Cível da Franca, n. 428, cx. 25, ff. 3r-42r, 1872, Arquivo Histórico Municipal, Franca, Brasil. 
parte das terras correspondentes à sucessão legítima de seu sogro e sua esposa, outras que comprou de Joaquim Severo da Costa, viúvo da sua cunhada falecida, e as terras no Sítio do Grotão. Este último foi permutado com suas filhas, seus genros e seus cunhados por umas terras localizadas na Fazenda Bebedouro ${ }^{4}$.

Em 1888 Garcia Duarte foi nomeado o Barão de Franca, data em que também acumulou mais propriedades a partir da compra de outras duas fazendas, cuja localização the forneceu um maior beneficio para sua fortuna econômica, permitindo-lhe o controle da área destinada para a construção da estrada de ferro. Também, os novos investimentos com plantações de café e melhoras estreitaram os laços econômicos com a região de Ribeirão Preto e Batatais. Por exemplo, sua nova Fazenda do Palmital ${ }^{5}$ tinha divisa com as terras do seu parente Bernardo Avelino de Andrade; também a Fazenda Santa Cecília fazia divisa com terras onde foi construída parte da Estrada de Ferro Mogiana, com propriedades de Francisco de Andrade Junqueira, com a Fazenda Restinga e as estradas que comunicavam São José da Bela Vista e Restinga com Franca.

A Fazenda do Palmital foi dividida em 1893, após a morte de José Garcia Duarte. Com casas e plantações de café, parte da propriedade foi herdada por seus genros Antônio Flavio Martins Ferreira e Luciano Vieira Santiago ${ }^{6}$. Também, a fazenda fazia divisa com as fazendas Montebello e Macaúbas, da propriedade da família de Martiniano Francisco da Costa, concunhado de José García Duarte e principal comprador da Fazenda Bebedouro ${ }^{7}$.

Martiniano F. da Costa desempenhou um papel central na distribuição de terras. O casamento com sua prima Maria Rita da Costa garantiu a herança de seu sogro José Bernardes e a doação de terras e escravos por parte de sua sogra Inácia Cândida. Para aumentar o seu capital, comprou

4 Divisão Fazenda Bebedouro, Cartório do 2º Oficio Cível da Franca, n. 109, cx. 152, ff. 2r-58r, 1881, Arquivo Histórico Municipal, Franca, Brasil.

5 Modesto e Maria Emerenciana tinham comprado a Fazenda Palmital de Antônio Flavio Martins Ferreira e não deixaram descendentes diretos. Inventário, Cartório do 1o Ofício Cível da Franca, n. 37, cx. 800, ff. 2r-48v, 1934, Arquivo Histórico Municipal, Franca, Brasil.

6 Embargos, Cartório do 1ํo Ofício Cível da Franca, n. 8.582, cx. 315, ff. 2r-145r, 1916, Arquivo Histórico Municipal, Franca, Brasil.

7 Divisão Fazenda Palmital, Cartório do 1ํ Ofício Cível da Franca, n. 498, cx. 325, ff. 2r-30v, 1893, Arquivo Histórico Municipal, Franca, Brasil. 
a parte da herança de seus primos, que residiam em Batatais. Tal herança correspondeu a quatro partes de terra nas propriedades Bebedouro, BoaVista e Macaúbas, no Termo de Franca, e outras na Fazenda Lageado, no Termo de São Simão, Comarca de Ribeirão Preto.

Além dessas terras, Martiniano compartilhou com seus irmãos outras propriedades que faziam parte da Fazenda Montebello, que herdou de seu pai Francisco Antônio da Costa, e com cerca divisória das fazendas Bebedouro e Restinga, de propriedade de seu cunhado Isaac Villela de Andrade $^{8}$. Quanto à família Andrade da Costa, da qual Martiniano Francisco da Costa foi personagem predominante, destaca-se que as terras herdadas de seu sogro foram divididas e vendidas, incentivando o crescimento de transações de terra no interior da família. Porquanto, a circulação das propriedades fortaleceu o acesso a uma variedade de terra e uma posição geográfica que permitiu abundância de rotas de comércio e da proximidade com outras regiões econômicas importantes. A posição das fazendas na região de Franca dependia das novas condições comerciais visíveis a partir do aumento de plantações de café.

A família de Martiniano F. da Costa, ambos os seus irmãos, sua esposa e cunhados tiveram uma participação diretamente relacionada com o cultivo do café. Assim como as famílias mencionadas acima, estes foram agrupados em sociedades comerciais, concentrando-se em torno da propriedade rural e do fortalecimento da lavoura cafeeira (Tosi, 2003, p. 273-317). Destaca-se que a influência econômica e política dos fazendeiros foi usada para receber os contratos do governo, a fim de participar nas decisões das empresas ferroviárias e conseguir determinar o traço e a localização nas suas propriedades das estações da "Companhia Mogiana de Estrada de Ferro e Navegação" 9 .

A estrada de ferro gerou uma variedade de alternativas entre as quais se destacaram maior velocidade entre as estações, eficiência no transporte das mercadorias e redução de custos ao conectar as suas fazendas

8 Divisão Fazenda Montebello, Cartório do 2o Ofício Cível da Franca, n. 87, cx. 152, ff. 1r-11r, 1879, Arquivo Histórico Municipal, Franca, Brasil.Ver Ação arbitral, Cartório do 1ํ Ofício Cível da Franca, n. 275, cx. 688, ff. 3r-25v, 1882, Arquivo Histórico Municipal, Franca, Brasil.

9 Registros de títulos, documentos e outros papéis, Cartório do 1o Ofício do Registro de Hypotecas, n. 122, p. 73-74, 1909; n. 122, p. 116, 1910; n. 256, p. 176, 1912 , Arquivo Histórico Municipal, Franca, Brasil. 
e a linha Mogiana com as estações da linha Paulista (Lamounier, 2010). Uma opção foi vender parte das propriedades para a empresa ferroviária, a fim de garantir a ligação entre as fazendas e a ferrovia. Este foi o caso de parte das terras da Fazenda Montebello, em Restinga, pertencentes a Isaac Villela de Andrade e sua esposa Ana Cândida de Andrade. Em 1896, as ditas terras foram vendidas à Companhia Mogiana sob a condição de se construir umas casas o mais próximo possível da linha de ferro para as máquinas de beneficiar café e para a Estação Restinga ${ }^{10}$.

Além disso, em 1887 Martiniano Francisco da Costa e sua esposa Maria Rita transferiram à Companhia Mogiana um terreno para a construção de uma estação e parte da ferrovia, incluindo o abastecimento de água de uma caverna nas proximidades ${ }^{11}$. Em 1900, Dorothea Claudina Villela também deu algumas terras de sua Fazenda Santo Antônio para a construção de uma estação da mesma companhia ${ }^{12}$.

\subsection{Divisão entre sócios e irmãos: Fazenda A Luisiana}

Reyes, Eleuterio e Florentino foram três irmãos colombianos que mantiveram uma relação estreita que só terminou com a morte de Reyes em 1905. Seu status como credores e comerciantes de imobiliário trouxe o reconhecimento entre o círculo de comerciantes na região. $\mathrm{O}$ poder econômico favoreceu-os não só exercendo cargos públicos, mas também integrando o pequeno número de comerciantes, que, além de controlar as rendas principais do Estado, foram seus principais contribuintes.

Em 1882, com seus amigos Miguel Parra e Juan José Benítez como testemunhas, Reyes González e seus irmãos, Florentino e Eleuterio, assinaram um contrato de companhia coletiva de comércio. Essa empresa vigorou sob o nome de Reyes González e Irmãos. A empresa foi planejada para existir por um período de quatro anos, com operações cujo objetivo era a importação de bens e mercadorias estrangeiras, e a exportação de máquinas, café, couro e outros produtos do país. No entanto, a função principal da casa comercial foi a gestão e disseminação

\footnotetext{
10 2ำ TNPTF, SP, livro 29, ff. 24r-25r, 1896; livro 37, ff. 71r-74r, 1900.

112 - TNPTF, SP, livro 11, ff. 29 v-30r, 1887.

12 2o TNPTF, SP, livro 37, ff. 50r-51r, 1900.
} 
de vários tipos de atividade comercial na região e em outros departamentos. Para esse fim, eles abriram sucursais nas povoações de Rionegro, Cúcuta, Pamplona e Ocaña, com agências de comissão nos portos marítimos de Barranquilla, na Colômbia, e de Maracaibo, na Venezuela.

Os irmãos González foram os únicos sócios da companhia. Não houve irmãos bem-sucedidos pertencentes a famílias proeminentes para facilitar as transações financeiras ou o acesso ao círculo comercial da época. Também não basearam a sua fortuna em herança. Portanto, eles não usaram redes familiares como a maioria dos comerciantes contemporâneos, que através do casamento formaram laços comerciais com estrangeiros que chegaram a Bucaramanga durante a segunda metade do século XIX (Duque, 2002).

No que diz respeito à sua família, González tinha três irmãos e seis irmãs, uma delas casada. $O$ perfil das cinco únicas mulheres não foi só de mulheres excluídas das atividades comerciais devido à ausência de um marido que as representassem ou as autorizassem a realizar negócios. Nem elas participaram de contratos de casamento com beneficio para as famílias envolvidas em várias empresas com os irmãos González. O trabalho das irmãs foi colaborar como compradoras das propriedades de Eleuterio Reyes e Florentino, que estavam em risco de ser encerradas por causa de créditos não cumpridos ou por quaisquer falhas nas empresas que diariamente estes formalizavam. O mais comum no seio da família González foi utilizar a forma jurídica de suas irmãs para proteger sua propriedade dos credores $^{13}$.

Sua Fazenda A Luisiana tinha uma estreita ligação com as regiões intermediárias entre Pamplona, Ocaña ${ }^{14}$ e Cúcuta. O movimento constante de mercadorias estrangeiras e produtos agrícolas de exportação, como o quinino e o café, precisou a compra e aquisição de meios de transporte, especialmente cavalos e mulas. Com o gado, a criação de

13 AHR, NPB, tomo 1, cx. 168, n. 96, ff. 241v-243r, 1888; tomo 2, cx. 151, n. 217, ff. 467r-468v, 1885, Arquivo Histórico Regional, Bucaramanga, Colômbia.

14 DO, n. 2.051, 1870.Vários exemplos mostram a importância da região, foi o caso da salina descoberta no "El Playón” ou "Mesa Rica”, localizado no sítio de San Pedro, Ocaña. Também, os vínculos e até mesmo reclamações civis que Reyes González tinha com as casas comerciais da dita cidade por negócios com o quinino explorado no Playón, como foi o caso da sociedade "José Domingo Jácome \& Hnos.", ou a “Compañía Industrial de Ocaña". NPB, tomo 3, cx. 134, n. 606, ff. 878v-879v; n. 607, ff. 879v-880v, 1881, Arquivo Histórico Regional, Bucaramanga, Colômbia. 
mulas foi um negócio que forneceu significativas rendas, devido à ausência da ferrovia; também o nível de compra e venda de mulas aumentou, levando a um acréscimo dos empréstimos.

Da mesma forma, o dito negócio aumentou as dívidas e transferências de ônus resultantes de créditos causados por fretes de cargas, ou a passagem dos cavalos e mulas por pontes e estradas construídas por particulares.Alguns exemplos mostram o caso de Reyes González como garante dos comerciantes de outras regiões com influência direta na Luisiana, e que mantinha ligações constantes com os comerciantes de Bucaramanga e Bogotá. Seus créditos na maioria dos casos foram apoiados pelas receitas geradas de bebidas alcoólicas ou de abate de bovinos ${ }^{15}$.

As redes dos irmãos González moviam-se desde Pamplona até Girón, onde realizavam empréstimos de consumo aos comerciantes de propriedade, colonos, especuladores de terras, que procuravam com tais empréstimos ingressar no negócio de bens imóveis ou ferroviários ${ }^{16}$. Assim, tinham no entorno deles um grupo maior de indivíduos distribuídos em várias regiões de Santander, na costa do Atlântico, na Venezuela, na Europa e nos Estados Unidos, ligados ao seu negócio de família por seu envolvimento na compra de café e importação de bens de consumo (Carreño, 2015).

\section{Mercados locais e redes de negócios}

\subsection{Bebedouro, fazenda no interior de Franca (SP)}

Por seu clima, sua topografia, seu solo fértil, seu modo de vida e pelos costumes de seus habitantes, São Paulo foi considerada uma das regiões mais atraentes do Brasil para colonos estrangeiros adaptados ao trabalho agrícola ${ }^{17}$. No interior, duas cidades foram descritas como futuros e prósperos centros comerciais. Ribeirão Preto, localizado no

\footnotetext{
15 NPB, tomo 3, cx. 84, s.n., ff. 1r-31r, 1883, Arquivo Histórico Regional, Bucaramanga, Colômbia.

16 NPB, tomo 1, cx. 154, n. 70, ff. 138r-141r, 1886; tomo 2, cx. 155, n. 67, ff. 54v-55v, 1886; NPB, tomo 1, cx. 154, n. 153, ff. 150r-152r, 1886,Arquivo Histórico Regional, Bucaramanga, Colômbia.

17 O Nono Distrito, n. 9, p. 3, 1882, Arquivo Histórico Municipal, Franca, Brasil.
} 
nordeste do estado de São Paulo e uma das áreas produtoras de café mais dinâmica na segunda metade do século XIX (Lopes, 2008, 2009; Souza, 2009; García, 1999; Lamounier, 2010), concorreu com Franca, uma cidade menor, com pequena população e baixa produção agrícola ${ }^{18}$.

Apesar de sua posição óbvia em Ribeirão Preto, Franca apresentou um grande crescimento econômico e populacional, antes da chegada da estrada de ferro com a Companhia Mogiana em 1887, e na lavoura do café em escala comercial em 1890. Concentrando-se em suas colinas (Colombo, 1922), no meio do rio Pardo e na divisa com Minas Gerais, no norte paulista (Cunha, 2009, p. 15), juntou-se ao que foi chamado inicialmente o Sertão do Rio Pardo e, desde o final do século XIX, novo Oeste Paulista, termo que se originou durante a expansão da produção de café do Vale do Paraíba.

Com a chegada da ferrovia e a expansão do cultivo de café entre 1890 e 1920, permaneceram as atividades econômicas tradicionais e a antiga estrutura de produção, levando ao seu crescimento e revitalização (Oliveira, 2006, p. 215). Ao lado delas, as transformações econômicas orientadas para a produção de café impeliram a riqueza, mudando e produzindo várias rendas econômicas, como aquelas registradas com a fundação dos bancos, as diversas formas de crédito, a compra de ações na empresa ferroviária (capital privado), a formação de sociedades comerciais, a mercantilização da terra urbana e as melhorias em cidades e praças públicas, ganhando mais espaço na riqueza global dos proprietários entre 1875 e 1885. Tempo em que os proprietários de terras também começaram a atuar no mercado a partir de uma grande incursão no negócio de café e na vida política (Faleiros, 2002, p. 28, 38; Ferreira, 2005).

A produção francana na sua prática tradicional em relação ao comércio regional foi consolidada com mais força a partir da introdução das plantações de café entre 1885 e 1887. Mais tarde, com a integração das estradas de ferro, a área de produção foi estendida para o mercado interno, sem deixar de lado a produção de gado e alimentos. No entanto, as transações de compra e venda de terras foram continuamente intensificadas, assim como a produção de mercadorias, o crescimento

18 O Nono Distrito, n. 33, p. 1, 1882; n. 50, p. 1-2, 1882; n. 51, p. 1, 3, 1882; n. 52, p. 1 , 1882, Arquivo Histórico Municipal, Franca, Brasil. 
da atividade industrial e o fornecimento interno (Oliveira, 2006, p. 23; Tosi, 2003, p. 33).

A posição de Franca como ponto de convergência entre São Paulo, Minas Gerais (Furtado, 2007, p. 211-212), Mato Grosso e Goiás foi marcada não só com a chegada dos trilhos da Mogiana, que deu um passo à frente nos meios de comunicação e transporte, como também influenciou o fim da escravidão em 1888, o desenvolvimento do processo de urbanização, o crescimento do comércio e dos serviços, as transformações políticas, como a Proclamação da República em 1889, e a entrada de novos imigrantes nacionais e estrangeiros na década de 1880 (Cunha, 2009, p. 45, 47).

Em 1892 foi percebida uma explosão do número de toneladas de café embarcadas na Estação da Mogiana em Franca (Faleiros, 2002, p. 30,33). Por conseguinte, a ferrovia levou a produção cafeeira capitalista para Franca. Apesar da existência de fazendas produtoras de café, aquelas foram pouco significativas, assim como os produtores de café, que possuíam pouca importância, em comparação com a produção e os produtores dos anos seguintes. Situação que mudou somente após a chegada da estrada de ferro (Faleiros, 2002, p. 65).

O espaço na área urbana de Franca começou um processo de transformação, consideradas de utilidade pública aquelas extensões de terras situadas no oeste da cidade, que foi denominado o melhor ponto comercial, sendo desapropriadas e transferidas para a Companhia Mogiana de Estradas de Ferro. As regiões Bom Jardim, São José da Bela Vista, Restinga, Ribeirão Corrente e Patrocínio do Sapucaí, consideradas as mais prósperas e populosas de Franca, fizeram conexão direta com a dita área, adquirindo um elevado valor comercial ${ }^{19}$. Com a extensão da linha ferroviária que cortou longitudinalmente Franca, foram estabelecidas as estações de Boa Sorte, Mandiú, Restinga e Cristais (Nascimento; Moreira, 1943, p. 2).

Entre os fatores que reforçaram o desenvolvimento dessa área, destacou-se a localização de um grupo de fazendas extensas e repartidas, desde o final do século XIX, entre os membros da mesma família e aqueles que entraram através do casamento ou constituição de sociedades.

19 Ação de desapropriação, Cartório do 1ํ Ofício Cível da Franca, CMF, n. 444, cx. 699, p. 2, 43, 1919, Arquivo Histórico Municipal, Franca, Brasil. 
Tal foi o caso da Fazenda Santo Antônio, no distrito de São José da Bela Vista, doada por Dorothea Claudina Villela a sua filha e seu genro em 1916, que estava sob a condição de não ser vendida, transferida ou hipotecada, sendo preservada para passar para a próxima geração ou ser vendida exclusivamente para os membros da família ${ }^{20}$.

Usando sua posição como um grupo dominante, com práticas burocráticas, e aproveitando a localização das propriedades e das trajetórias de comércio que organizavam, eles monopolizaram mais terras, segurando sua entrada no círculo comercial. Por conseguinte, no último quartel do século XIX, a unidade de produção em larga escala foi consolidada na região de Franca precisamente com a cafeicultura, adquirindo sua maior expressão com o uso da ferrovia (Tosi, 2003, p. 37-38).

Uma das transformações econômicas que marcaram a história de Franca durante a virada do século foi a transação de imóveis urbanos e rurais (Oliveira, 2006, p. 110). Os proprietários de terras foram inicialmente lavradores e compradores de terras localizadas perto dos rios e das estradas principais para facilitar a conexão com outras regiões e para a expansão agrícola. Eles não investiram todo o capital em uma única atividade produtiva, e não reconheciam a monocultura como uma oportunidade para aumentar os seus ativos, uma vez que eram, ao mesmo tempo, os principais produtores de café e criadores de gado (Oliveira, 2006, p. 145).

\subsection{Fazenda A Luisiana na região oriental colombiana}

Em Santander, área norte da cordilheira oriental da Colômbia, o café inaugurou as primeiras formas de produção, que, nas duas últimas décadas do século XIX, se estenderam a toda a região andina colombiana, em particular no departamento de Cundinamarca, no sudoeste de Antioquia e Tolima, na Cordilheira Central; todos eles reconhecidos também por sua proximidade com o rio Magdalena, via fluvial significativa, que ligava o centro do país com a costa do Caribe (Bergquist, 1999, p. 58; Vergara, 1974, p. 351-353, 363, 664).

20 Inventário, Cartório do 1ํo Ofício Cível da Franca, n. 61, cx. 387,ff. 7, 15r, 16r, 1916, Arquivo Histórico Municipal, Franca, Brasil. 
O deslocamento da produção de café e do quinino dependeu da existência de terrenos adequados e da disponibilidade de mão de obra, abundante na região da Cordilheira Central. Na região, o café expandiu-se rapidamente, e a fazenda reforçou as redes de comunicação nos vários pisos térmicos e nos extensos declives da terra temperada, para ligar as terras frias com as quentes e procurando a saída para os portos marítimos. Além disso, introduziu os laços comerciais e financeiros com o mercado mundial (Palacios, 2009, p. 58-59).

Também, a concentração da propriedade levou à acumulação de grandes áreas, divisão e posterior venda, que, apesar de seus preços excessivos, não diminuiu o acelerado processo de compra e venda mantido em áreas pertencentes a um estreito círculo de famílias (Palacios, 2009, p. 180-182).

No meio dos paramos e precipícios localizados entre os nós e os vales das montanhas orientais e ocidentais e as cadeias de montanhas, que segundo os viajantes foram capazes de repelir qualquer progresso (Carreño, 2007,p. 17;Valderrama, 1948, p. 192;Ancízar, 1956, p. 160,375; Hettner, 1966, p. 140), e num importante conjunto de afluentes ${ }^{21}$ que comunicavam com o rio Magdalena, encontravam-se Bucaramanga, o Distrito de Rionegro e nas suas proximidades a Fazenda A Luisiana.

Para abrir estradas, gastaram grandes quantias de dinheiro sem qualquer resultado visível. O solo, composto de argila e pântano, com sulcos de lama, marcados com o ritmo constante das mulas, era, sem dúvida, o obstáculo geográfico mais característico desafiado durante o século XIX. Apenas alguns caminhos foram construídos, e, em outros casos, aqueles que começaram quase nunca concluíram (Hettner, 1966, p. 277-281). A presença de pensões, vendas e pousadas facilitaram o trânsito nas estradas, beneficiando os viajantes e tropeiros com suas mulas ${ }^{22}$, obrigados a deter as cargas até que os caminhos fossem restaurados, uma situação que podia durar dias, até mesmo semanas (Dominguez et al., 2004, p. 282).

Assim, na área que compreendia a Fazenda A Luisiana, o governo deu impulso à reconstrução de uma estrada para aproximar o Porto de

21 GS, n. 2.142 , p. $3.324 ;$ n. 2.143 , p. 3.328; n. 2.147, p. 3.344; n. 2.148, p. 3.347-3.348; n. 2.149, p. 3.352, 1889, Arquivo Histórico Regional, Bucaramanga, Colômbia.

22 GS, n. 209, p. 225-226, 1864; AHR, SCS-FJB, cx. 15, ff. 1, 4r, 12r, 13r, 1898, Arquivo Histórico Regional, Bucaramanga, Colômbia. 
Botijas. Além disso, promoveu vários projetos para localizar, perto dos caminhos, grupos de famílias dedicadas à rotação de culturas e criação de gado, a fim de ajustar-se ao projeto de povoamento ${ }^{23}$. Foram localizadas fazendas cercadas de terra, plantações e campos ao lado de "casas de barro, varas e telha", cabanas de palha e outras variedades, com máquinas e ferramentas, moinhos, plantações de café, cacau, cana-de-açúcar, tabaco, bananas, mandioca e grama artificial ${ }^{24}$. Todas aquelas produções foram compensadas pelo crescimento na produção de piquetes de grama e de aluguel de potreiros para a manutenção de gado (touros, bois e novilhas), burros, porcos, éguas, cavalos e mulas ${ }^{25}$, tornando-se um negócio muito rentável para grande parte do século XIX (Carreño, 2007, p. 157).

Nesses locais, além de máquinas, borracha, resinas e bálsamos silvestres, havia minério de ouro, cobre, prata e pedras preciosas ${ }^{26}$. Produtos, como café, couro, algodão e chapéus de palha, foram vendidos por empresas comerciais localizadas em Bucaramanga, com utilidades que incentivaram o desenvolvimento da capital da província e o aumento das fazendas localizadas entre os distritos de Lebrija e Rionegro, nesse caso a Fazenda A Luisiana ${ }^{27}$.

\section{A fazenda: ponto de partida para beneficiar-se das vias de comunicação e das rotas comerciais}

\subsection{A estrada de ferro e a Fazenda Bebedouro}

Os discursos sobre a importância econômica, em termos de produção de café e acesso a rotas comerciais, eram comuns em jornais e debates da Assembleia Provincial. Para compreender o interesse que marcou

\footnotetext{
23 GS, n. 1.337, p. 802, 1879, Arquivo Histórico Regional, Bucaramanga, Colômbia.

24 AHR, SCT-FJB, cx. 2, f. 17, 1888, Arquivo Histórico Regional, Bucaramanga, Colômbia.

25 AHR, SCE-FJB, cx. 11, ff. 1-41, 1886; SCE-FJB, cx. 5, ff. 3, 4v, 5, 62, 63r, 1877 , Arquivo Histórico Regional, Bucaramanga, Colômbia.

26 AHR, SCE-FJB, cx. 2, ff. 1, 19v-20r, 1883; SCT-FJB, cx. 2, ff. 1, 2r, 9, 10r, 12r, 1888, SCE-FJB, cx. 5, ff. 4, 5r, 1889, Arquivo Histórico Regional, Bucaramanga, Colômbia.

27 O último foi projetado como o espaço principal para a expansão cafeeira.
} 
esses argumentos, devem ser analisadas as regiões de Ribeirão Preto, Batatais e Franca, identificadas como rivais não tanto pela capacidade da produção agrícola, mas particularmente por grupos de agricultores estabelecidos na zona, que procuravam promover ante o governo estadual a defesa da agricultura e do comércio. Por isso, em 1884 os líderes do partido, o liberal Francisco Barbosa Lima e o conservador José Garcia Duarte, fundaram o "Clube da Lavoura e do Comércio" (Melo, 1995, p. 43).

Além disso, a passagem da linha ferroviária da Companhia Mogiana de Franca estava sempre no centro das discussões por duas versões diferentes. A primeira considerou a posição topográfica do município de Franca como um dos principais obstáculos para o desenvolvimento comercial por causa da distância dos portos marítimos e dos grandes rios. Em segundo lugar, o conflito entre Francisco Barbosa Lima e Martinho Prado Júnior sobre a extensão da linha Mogiana para passar pela região de Franca foi exibido não só na arena política. Antes de realizar atividades públicas, Martinho Prado Júnior era fazendeiro; assim, sua proposta para alterar a rota original da linha ferroviária Mogiana tinha interesses comerciais.

O traço, segundo Martinho, foi levar a ferrovia até Ribeirão Preto, cidade republicana e um grande potencial de café. Entre seus projetos encontrava-se que a linha ferroviária passara perto das suas fazendas, aumentando sua dinâmica comercial e concessão de privilégios em comparação com outros municípios, levando à "competição entre capitais privados” (Faleiros, 2002, p. 50-52). Isso reforça a ideia de Rogério Faleiros, que constatou, a partir dos protocolos de compra e venda de café, que Ribeirão Preto foi a cidade onde grande parte dos negócios da região chamada Mogiana foram feitos, mas que, por sua vez, dependia dos vendedores de café provenientes de diversos municípios da região, incluindo Franca, Batatais, Ituverava, Orlândia, Tambaú, Sales Oliveira, Cravinhos, Guará, São Simão, Brodósqui, Sertãozinho, Rifaina e São José da Bela Vista (Faleiros, 2007, p. 127-128).

Para Barbosa Lima, as melhores oportunidades de negócios estavam em Sacramento, localizadas no meio de Franca e Uberaba, também identificado como um dos portos comerciais mais importantes do interior. Havia estabelecimentos reconhecidos, entre os quais se destacaram aqueles de Simão Caleiro, personagem muito próximo à Fazenda Be- 
bedouro e que mantinha ligações com o centro de São Paulo ${ }^{28}$. Assim, o investimento em Franca foi estendido para as suas áreas mais próximas, particularmente para o nordeste. Lá, os investidores se moveram em um círculo com relações regionais marcadas, através do qual passava a linha ferroviária Mogiana; destaca-se, por exemplo, Cristais, Restinga e Igarapava $^{29}$.

Tornou-se claro que a linha Mogiana, depois de deixar Ribeirão Preto, passara por Batatais, Franca e Sacramento, para terminar em Uberaba.Assim, no dia 11 de abril de 1887 a Estação de Franca foi inaugurada, para continuar em direção ao rio Grande, atravessando-o no dia 5 de março de 1888, e inaugurando em 1889 as estações de Conquista, Sacramento e Uberaba.

A concorrência entre as empresas ferroviárias, as áreas comerciais e a própria geografia concretizaram o projeto para levar a linha Mogiana até Franca. O próspero comércio de sal, gado e outros bens, movimentado na região de Sacramento e ligado com o centro de São Paulo, promoveu a construção das estações em várias partes da região. No âmbito dessa iniciativa, exerceram influência os comerciantes que tinham acesso a redes de negócios em Minas Gerais, particularmente em Sacramento. As conexões que Simão Caleiro tinha projetado através dos seus estabelecimentos comerciais nesse distrito, permitem reconhecer que o seu interesse na ferrovia lhe oferecia diversos beneficios, tais como o aumento da quantidade de cargas enviadas, os embarques rápidos e o ingresso a centros de comércio novos.

A sociedade "Simão Caleiro \& Filhos" compartilhou negócios com Antônio Elói Casimiro, o "Barão da Ponte Alta”, residente em Uberaba, a quem ele comprou um terreno entre as cidades de Sacramento e Uberaba. A propriedade nomeada pelo comprador como Fazenda "Emília"30 mostrou também as conexões que ligaram Simão com o

28 O Nono Distrito, n. 14, p. 3; n. 15, p. 1; n. 34, p. 1, 3; n. 50, p. 1-2; n. 51, p. 1, 3; n. 52, p. 1-2, 1882, Arquivo Histórico Municipal, Franca, Brasil.

29 Registros de títulos, documentos e outros papéis, Cartório do 1 @ Ofício do Registro de Hipotecas, n. 57, p. 37-38, 1908.

30 Inventário, Cartório do 2o Ofício Cível da Franca, n. 693, cx. 1.437, ff. 3r-58r, 1902, Arquivo Histórico Municipal, Franca, Brasil. Sacramento foi uns dos mais importantes centros do comércio do interior. Dos produtos que passaram por ali, o sal foi o mais comum e aquele que ocupou um lugar importante no intercâmbio econômico entre Franca e Minas Gerais. Cerca de 60 mil pacotes de sal saíram cada ano daquela região para o centro de São Paulo, além de outras mercadorias. 
renomado comerciante de Patrocínio do Sapucaí, João de Faria, que, com Higino de Oliveira, foram fiadores e principais pagadores durante o processo de compra da dita fazenda (Faleiros, 2002, p. 56-58).

Desse modo, o funcionamento das redes de intermediários locais foi muito importante para o negócio de compra e venda de produtos agrícolas, particularmente do café destinado à exportação. A partir do século XX, o café em coco de Itirapuã, na região de Patrocínio do Sapucaí, foi transportado para as fazendas localizadas na parte nordeste, entre Franca e Ibiraci, na fronteira com Minas Gerais e propriedades de Higino Caleiro, filho de Simão Caleiro. As áreas incluídas nas fazendas "Coração da Palestina", "Aliança” e "Casa Seca" foram muito importantes para a produção de café, causando litígios entre os proprietários pela abertura de estradas para o transporte das colheitas para Franca ${ }^{31}$.

\subsection{Caminhos e trilhos na Fazenda A Luisiana}

$\mathrm{Na}$ Colômbia, apesar da formalidade dos limites registrados nas escrituras, as demandas sobre os direitos de propriedade eram comuns na década de 1880, assim como também as reclamações pelos prejuízos causados pela incursão de exploradores do quinino nas terras que compreendiam a área onde a Fazenda A Luisiana foi localizada. Entre os portos de Botijas e Papayal ${ }^{32}$, denota-se a posse das melhores terras por um grupo de comerciantes que procuravam acumular as áreas mais próximas às rotas de comércio. Observando-se, por exemplo, que aqueles que afirmavam que eram vizinhos dos distritos de Matanza e Rionegro (Fazenda A Luisiana), faziam parte de outras jurisdições e tinham relação direta com a área de exploração, como Cáchira, Lebrija e Pamplona ${ }^{33}$.

Partindo de Rionegro para A Luisiana, considera-se uma área caracterizada pela presença de extensas pastagens, onde se alimentou o gado

31 Execução por custas, Cartório do 2o Ofício Cível da Franca, n. 876, cx. 206, ff. 2r-5r, 1908; Nunciação de obra nova, n. 765, cx. 190, ff. 2r-55r, 1902; Execução hipotecária, n. 25, cx. 222, ff. 2r-5r, 1909, Arquivo Histórico Municipal, Franca, Brasil.

32 AHR, SCS-FJB, cx. 4, n. 555, ff. 1r-10r, 1882, Arquivo Histórico Regional, Bucaramanga, Colômbia.

33 AHR, NPB, tomo 2, cx. 137, n. 171, ff. 513v-515v, 1882; tomo 3, cx. 129, n. 457, ff. 72r-74r, 1880; tomo 4, cx. 135, n. 675, ff. 999v-1.006r, 1881, Arquivo Histórico Regional, Bucaramanga, Colômbia. 
procedente do departamento de Bolívar com direção até Rionegro, espaço onde sobressaía a fazenda, rodeada por pequenas casas de pousadas ${ }^{34}$, distantes dos lugares onde foi localizada a linha férrea, ou onde havia áreas específicas para minas ou terras de uso público particular ${ }^{35}$.

Naquela área, Reyes González procurou um pedido de patente para a abertura de uma estrada e uma ponte, para ligar os departamentos de Ocaña e Soto. Nesse caso, o Artigo 26 do Código de Obras Públicas de 1886 permitiu a abertura de novas estradas, desde que o indivíduo ou a associação que iria realizar o trabalho apresentasse provas suficientes sobre o beneficio econômico para o Estado. Em sua petição, González considerava importante a construção desta rota entre Rionegro e o rio Cáchira, assim como a ponte próxima à sua Fazenda A Luisiana, como uma forma de promover os interesses dos dois departamentos.

Segundo González, se a estrada uma vez aberta não aportasse a lucros, seria ele mesmo quem padeceria prejuízos, tendo em conta a perda do capital investido na sua construção. Mesmo tendo observado vantagem incalculável para o Departamento de Soto, sua preocupação imediata foi a construção da estrada muito perto da sua fazenda. Tal privilégio foi concedido, definindo um prazo para se construir de 6 meses $^{36}$. Com uma duração de 25 anos, o empresário podia cobrar pedágio sobre a importação e exportação de cargas, com exceção dos itens gratuitos declarados de todos os impostos ou execução fiscal, pelo trânsito de gado, mulas e cavalos. Por sua vez, durante o tempo do privilégio a estrada não seria tributada, nem as obras a ele adjacentes com contribuição pública de qualquer tipo ${ }^{37}$.

Das estradas que foram projetadas entre 1880 e 1900, destaca-se o caminho de Bucaramanga até Ocaña por Rionegro, na confluência dos rios Lebrija e Rionegro, através do qual até esse ponto tinha sido construído pela "Companhia empresária do caminho de ferro de $\mathrm{Bu}-$ caramanga para Sabana de Torres" (García, 1982, p. 371). Essa rota era percorrida em cinco dias, aproximadamente, com um itinerário que começava em Bucaramanga, passava por Rionegro, daí à Fazenda A

\footnotetext{
34 GS, n. 2.143, p. 3.328, 1889, Arquivo Histórico Regional, Bucaramanga, Colômbia. 35 GS, n. 3.277, p. 335, 1898, Arquivo Histórico Regional, Bucaramanga, Colômbia.

36 GS, n. 13, p. 52-53, 1886, Arquivo Histórico Regional, Bucaramanga, Colômbia.

37 GS, n. 1.853, p. 2.163, 1886, Arquivo Histórico Regional, Bucaramanga, Colômbia.
} 
Luisiana e depois até o rio Cáchira, para finalmente chegar até Ocaña. Esse trajeto foi muito utilizado por comerciantes e moradores dos municípios de Bucaramanga, Rionegro, Girón e Lebrija ${ }^{38}$.

Portanto, a sociedade "Reyes González \& Irmãos" junto com Francisco R. Ordóñez estabeleceram a dita sociedade para construir umas vias que continuariam as obras da estrada de ferro de Puerto Wilches. Assim, a construtora foi autorizada para principiar as obras, junto com a concessão de terras e com o privilégio exclusivo sobre os armazéns para o depósito das cargas.

A pouca possibilidade para construir uma linha ferroviária nessa área levou à adjudicação de contratos, para em seu lugar abrirem-se caminhos. Assim, em 1885, quando entrou em vigor o caminho, Reyes González contratou com o Governo do Estado o aluguel da renda de pedágio dos caminhos de Soto ao rio Magdalena para o período de três anos. Seu dever era compor e manter em bom tráfego as vias, o mesmo que construir armazéns próximos ao rio Magdalena no Porto de Botijas, com funcionários suficientes para evitar o contrabando. Também lhe foi concedido o direito de cobrar pedágio para a passagem de carga de importação e exportação ${ }^{39}$.

Outra via importante para a região e mesmo para González foi o caminho de Cúcuta para Ocaña através do Playón. Esse caminho indicou as relações comerciais que existiam entre essas duas cidades conhecidas ${ }^{40}$, vinculando-se com as estradas e os rios que chegavam à costa norte da Colômbia, tornando-se um dos projetos mais importantes não só pelos ingressos de dinheiro, mas também pela recuperação do comércio de Cúcuta, para evitar o pagamento excessivo de impostos exigidos pelo governo venezuelano.

Embora não fosse pouco mais que uma trilha, o traçado do caminho interessou a todos aqueles que transportavam gado desde o Estado de Magdalena e Cúcuta. Esta foi outra razão para acrescentar as atividades comerciais da companhia Reyes González \& Irmãos, os quais em 1892 foram associados com Manuel Roca, um residente de Ocaña, para criar

\footnotetext{
38 GS, n. 2.142, p. 3.324, 1889, Arquivo Histórico Regional, Bucaramanga, Colômbia.

39 NPB, tomo 2, cx. 155, n. 309, ff. 327r-335v, 1886, Arquivo Histórico Regional, Bucaramanga, Colômbia.

40 GS, n. 2.149, p. 3.351, 1889.
} 
a empresa Gonzáles \& Roca Rincón. O seu objetivo foi obter uma concessão do Estado de Magdalena, para abrir um caminho para servir na condução de gado até a Fazenda A Luisiana e, também, para obter a adjudicação dos pedágios sobre as cargas e os passageiros em trânsito pela zona ${ }^{41}$. Sua fazenda ficava no meio do caminho, gerando lucros, oportunidade que aproveitou González para fazer pedido ao Estado de conceder privilégio sobre o caminho por $20 \mathrm{anos}^{42}$.

Os alegados obstáculos impostos na fronteira com a Venezuela não eram motivos suficientes para que Reyes González e sua companhia comercial continuassem interessados na introdução de mercadorias estrangeiras desde Maracaibo, cuja entrada na Colômbia foi realizada pelos portos fluviais próximos a Cúcuta. Foi assim que, em 1885, a empresa assinou um contrato de aluguel sobre o direito de consumo de mercadorias estrangeiras nesse departamento ${ }^{43}$.

Nas concessões solicitadas por González, também se concentrou um projeto comum de ligação entre Bucaramanga e os distritos de café próximos de Cúcuta. Essas estradas, consideradas centrais e de utilidade pública, ligaram os distritos de Suratá, Cachirí e Baguechecom Arboledas, reconhecida área cafeeira de finais do século XIX. Outro interesse nessa linha foi ligar a província de Cúcuta com Puerto Wilches e as estações ferroviárias a construírem na zona. Dessa forma, todo o café de Arboledas e de grande parte da Província de Cúcuta poderia ser enviado para o Magdalena, em vez de sair para a Venezuela ${ }^{44}$.

Também outro privilégio foi concedido, mas dessa vez ao comerciante Rinaldo A. Goelkel, para construir um caminho de freio para comunicar o município de Arboledas com Bucaramanga, na Província de Soto. Foi assim que as estradas foram aumentando, para permitir e facilitar o desenvolvimento do comércio de Arboledas, Chinácota, Bochalema, Gramalote, Salazar e Cucutilla, todos eles produtores de café. Além disso, essa via resultava de grande importância para o comércio

\footnotetext{
41 NSB, tomo 5, n. 873, ff. 3.066v-3.072r, 1892, Arquivo Histórico Regional, Bucaramanga, Colômbia.

42 NPB, tomo 2, cx. 155, n. 421, ff. 464v-471v, 1886, Arquivo Histórico Regional, Bucaramanga, Colômbia.

43 NPB, tomo 3, cx. 156, n. 465, ff. 508r-512r, 1886, Arquivo Histórico Regional, Bucaramanga, Colômbia.

44 GS, n. 2.770, p. 5.835, 1894, Arquivo Histórico Regional, Bucaramanga, Colômbia.
} 
de importação e exportação das províncias de Cúcuta e Pamplona, considerando o cruzamento desta com a estrada que ligava a Província de Soto com Ocaña, pela proximidade dos rios Cáchira e Lebrijae perto da Fazenda A Luisiana ${ }^{45}$.

\section{Considerações finais}

Essa história de duas regiões diferentes é um estudo sobre a circulação e intercâmbio acontecidos nas províncias interiores do Brasil e da Colômbia, durante o período de auge das fazendas agrícolas, principalmente do café. Para uma maior centralidade do tema, usou-se o caso de duas fazendas sobre as quais convergiram os interesses de duas famílias com preferências e estratégias muito dinâmicas e com suficiente informação para se comparar e para analisar como elas tiveram influência na construção de vias de comunicação nas suas proximidades. A informação sobre as fazendas foi escassa em relação a contas, notas fiscais, nome de empregados, contratos e cartas. Por isso, os arquivos de cartórios, os acervos judiciais e os inventários constituíram-se, quase exclusivamente, no ponto de referência para reconhecer a frequência dos vínculos entre os fazendeiros e os comerciantes com as regiões onde desenvolveram suas atividades. Assim, tanto no Brasil como na Colômbia os fazendeiros apropriaram-se das terras próximas às fazendas, para ligá-las às vias de comunicação que conectavam com outras regiões comerciais com as quais tinham negócios.

Esta pesquisa foi baseada em comparações, para argumentar que as estratégias empregadas pelos grupos socioeconômicos no Brasil e na Colômbia, o uso de fazenda como suporte e os capitais fornecidos pelo plantio de produtos primários ajudaram para garantir a incursão em outros negócios. Por sua vez, os proprietários apoiaram-se nos laços políticos, a fim de penetrarem e se fortalecerem no círculo mercantil

45 GS, n. 3.343, p. 601-602, 1899. Em 1888, o Conselho encarregado da melhora do rio Lebrija foi formado pelo governador do Estado de Santander, por Adolfo Harker e por Reyes González, com o alvo de facilitar a navegação a vapor. Com essa finalidade, foi atribuída a soma de $\$ 500$ mensais retirados dos recursos captados pelo imposto fluvial em Barranquilla. GS, n. 2.044, p. 2.929, 1888, Arquivo Histórico Regional, Bucaramanga, Colômbia. 
emergente, consumidor e moderno. Assim, durante os primeiros anos do século XX, as variáveis que definiram aos fazendeiros foram o ingresso no comércio através da criação de bancos e estabelecimentos comerciais e serviços, a modernização das cidades através de vários investimentos e a participação política. Essas variáveis decorrentes de trocas sociais não foram dadas de antemão.

Durante a segunda metade do século XIX, no contexto político e socioeconômico dos dois países, a participação de um grupo de pessoas com ligações entre parentes e vizinhos ajudou a destacar vários aspectos da vida cotidiana de territórios relativamente desconhecidos ou, em alguns casos, menores pela baixa produção e pelo baixo investimento, assim como a baixa representatividade em termos nacionais e internacionais. A Fazenda Bebedouro, bem como a Fazenda A Luisiana, exerceram a função de pontos estratégicos para a rede de caminhos e estradas de ferro. Também foram o centro da vida rural próxima a cidades capitais, como Ribeirão Preto e Bucaramanga, respectivamente, fornecendo produtos primários e visando a fortalecer as linhas comerciais em direção aos mercados vizinhos e nacionais.

Desse modo, a concentração em um lugar específico, tendente ao localismo, não impediu afiançar as ligações com os mercados regionais ou estrangeiros. A esse respeito predominam empresas comerciais, dentre as quais algumas foram de curta duração, outras foram transformadas em relação aos seus parceiros ou fins de negociação; eles mudaram o nome da empresa e tiveram a possibilidade de incorporar-se às demandas econômicas do novo século, possíveis redes através da construção de estradas, rodovias e ferrovias, para intensificar a produção e o transporte de bens de consumo relacionados com a importação de bens e a exportação de produtos agrícolas.

Este artigo mostrou, num primeiro momento, que os produtos agrícolas, como café e quinino, foram o principal produto de exportadores agrícolas no Brasil e na Colômbia, no final do século XIX, respectivamente. Por conseguinte, o apogeu desses produtos transformou gradualmente o negócio, orientando o interesse de redes locais e regionais para novas formas de associação familiar e de participação política. Os grupos analisados nos dois países construíram redes para garantir a sua autonomia no governo, a fim de introduzir os seus projetos e controlar ambos os mercados e rotas de comércio. Para investir em vias de comu- 
nicação, os fazendeiros fizeram uso de suas fazendas agrícolas e de sua proximidade das rotas comerciais com o mercado mundial.

\section{Fontes}

\section{Brasil}

ARQUIVO Histórico Municipal “Capitão Hipólito Antônio Pinheiro” - Franca (SP) (AHMUF)

Livros cartoriais (Cartório do Primeiro Tabellião de Franca).

Jornais: O Nono Distrito, O Aviso, Tribuna de Franca.

2ำTABELIÃO de Notas e de Protesto de Letras e Títulos de Franca (SP) (2ํTNPTF) Escrituras.

\section{Colômbia}

ARQUIVO Histórico Regional (AHR), Bucaramanga-Colômbia

Fondo: Notariales-Notaria Primera de Bucaramanga (NPB) e Notaría Segunda de Bucaramanga (NSB).

Fondo: Judicial de Bucaramanga (FJB) - século XIX-XX.

SECCIÓN: Civil-Ejecutivo (SCE), Civil-Sociedades (SCS), Civil-Tercerías (SCT)

Fondo: Publicaciones oficiales: Gaceta de Santander (GS), Diario Oficial (DO).

\section{Referências bibliográficas}

ABRAHÃO, Fernando Antônio. Trabalho familiar e inserção social na economia cafeeira. Campinas:1870-1940. SIMPOSIO: FAMILIAS, NEGOCIOSY EMPRESAS EN LA AMÉRICA LATINA, 1850-1930. II CLADHE, 2010 Ciudad de México. Disponível em < http://www.economia.unam.mx/cladhe/listado_ponencias.php? iSimposio $=20 \&$ NomSimposio $=$ Familias, $\% 20$ negocios $\% 20 \mathrm{y} \% 20$ empresas $\% 20 \mathrm{en} \% 20$ la\%20Am\%C3\%A9rica\%20Latina,\%201850-1930>. Acesso em 15/3/2015.

ANCÍZAR, Manuel. Peregrinación del Alpha. Por las provincias del Norte de la Nueva Granada, en 1850-1851. Bogotá: Empresa Nacional de Publicaciones, 1956.

BAUER, Arnold. América espanhola rural, 1850-1930. In: BETHELL, Leslie (org.). História da América Latina, de 1870 a 1930.V. 4. São Paulo: EDUSP, 2009, p. 209-246. BERGQUIST, Charles. Café y conflicto en Colombia (1886-1910): la Guerra de los Mil Días, sus antecedentes y consecuencias. Bogotá: Banco de la República/El Áncora, 1999. 
BÉRTOLA, Luis; OCAMPO, José Antonio. El desarrollo económico de América Latina desde la Independencia. México: FCE, 2013, cap. 3.

BOTERO, Fernando. La industrialización en Antioquia. Génesis y consolidación, 19001930. Medellín: Hombre Nuevo, 2003, cap. II, III.

BULMER-THOMAS, Víctor. The economic history of Latin America since Independence. Cambridge: University Press, 1996.

CAMELUCCI, Anderson. Crise monárquica e as experiências de República no município de Franca (1880-1906). Franca: UNESP, 2008 (Dissertação de Mestrado em História da UNESP).

CARREÑO, Clara. Construir caminos para conducir cargas y especular con tierras: los caminos de Lebrija y Sogamoso en el Departamento de Soto, 1865-1885. Bucaramanga:UIS, 2007 (Trabajo de Grado en Historia da UIS).

CARREÑO, Clara. Conducir cargas e intercambiar mercancías: los caminos de Lebrija y Sogamoso en la segunda mitad del siglo XIX. Anuario de Historia Regional $y$ de las Fronteras, v. 14, p. 225-244, 2009.

CARREÑO, Clara. Puertos locales y bienes de consumo: importación de mercancías finas en Santander, Colombia, 1870-1900. Am. Lat. Hist. Econ., v. 22, n. 1, p. 85-114, 2015.

CHEVALIER, François. La formación de los latifundios en México. Haciendas y sociedad en los siglos XVI, XVII y XVIII. México: FCE, 1999.

COELHO PRADO, Maria Ligia. Repensando a história comparada da América Latina. Revista de História, n. 153, p. 11-33, 2005.

COLOMBO, Guido. O Brasil illustrado - Commercio - Indústria - Agricultura. Rio de Janeiro, 1922.

CUNHA, Maísa Faleiros da. Demografia e família escrava. Franca (SP), século XIX. Campinas: UNICAMP, 2009 (Tese de Doutorado em Demografia da UNICAMP).

DOMINGUEZ, Camilo et al. Geografía física y política de la Confederación Granadina.V. 4. Bogotá: UNAL/UNICAUCA, 2004.

DUQUE, María Fernanda. Comerciantes y empresarios de Bucaramanga (1857-1885): una aproximación desde el neoinstitucionalismo. Historia Crítica, n. 29, p. 149-184, 2002.

FALEIROS, Rogerio Naques. Homens do café. Franca (1880-1920). Campinas: UNICAMP, 2002 (Dissertação de Mestrado em História Econômica da UNICAMP).

FALEIROS, Rogério Naques. Fronteiras do café: fazendas e “colonos” no interior paulista (1917-1937). Campinas: Instituto de Economia, Universidade Estadual de Campinas, 2007 (Tese de Doutorado em Economia Aplicada).

FERREIRA,Valdir. Homens do crédito: o fabriqueiro da Igreja e acumulação em Franca (1880-1929). Franca: UNESP, 2005 (Dissertação de Mestrado em História da UNESP).

FLORESCANO, Enrique (org.). Haciendas, latifundios y plantaciones en América Latina. México: Siglo XXI, 1975.

FLORESCANO, Enrique. A formação e a estrutura econômica da fazenda na Nova 
Espanha. In: BETHELL, Leslie (org.). História da América Latina: a América Latina colonial (II). São Paulo: EDUSP/Fundação Alexandre de Gusmão, 1999.

FRANCO, M. Almanack de Franca. Franca: Editorial de São Paulo, 1902.

FURTADO, Celso. Formação econômica do Brasil. São Paulo: Companhia das Letras, 2007.

GARCÍA, José. Crónicas de Bucaramanga. Bogotá: Banco de la República, 1982.

GARCÍA, Maria Angélica Momenso. A cafeicultura e a expansão do capitalismo. Economia \& Pesquisa, v. 1, n. 1, p. 7-16, 1999.

HETTNER, Alfred. La cordillera de Bogotá. Resultados de viajes y estudios, 1892. Bogotá: Banco de la República, 1966.

LAMOUNIER, María Lúcia.A Companhia Mogiana de Estradas de Ferro: investimentos e negócios no novo Oeste Paulista (São Paulo, 1870-1914). SIMPOSIO: FAMILIAS, NEGOCIOS Y EMPRESAS EN LA AMÉRICA LATINA, 1850-1930. II CLADHE, 2010, Ciudad de México. Disponível em <http://www.economia. unam.mx/cladhe/listado_ponencias.php?iSimposio $=20 \&$ NomSimposio $=$ Famili as, $\% 20$ negocios\%20y\%20empresas\%20en\%20la\%20Am\%C3\%A9rica\%20Latina,\%20 1850-1930>. Acesso em 13/2/2015.

LEVI, Giovanni. A herança imaterial: trajetória de um exorcista no Piemonte do século XVII. Rio de Janeiro: Civilização Brasileira, 2000, p. 7-37.

LOPES, Luciana. Café, riqueza e famílias. Ribeirão Preto na segunda metade do século XIX. História e Economia. Revista Interdisciplinar, v. 4, n. 1, p. 133-156, 2008.

LOPES, Luciana. Uma economia em formação: um estudo sobre a composição da riqueza em Ribeirão Preto com base nos inventários post mortem, 1866-1888. Revista do Centro Universitário Barão de Mauá, v. 2, p. 8-24, 2009.

MACHADO, Absalón. El café en Colombia a principios del siglo XX. In: MISAS, Gabriel (org.). Desarrollo económico y social en Colombia. Siglo XX. Bogotá: Cátedra Manuel Ancízar-UNAL, 2001.

MACHUCA, Laura. Hacienda y movilidad social en Yucatán en la primera mitad del siglo XIX. Letras Históricas, n. 5, p. 81-100, 2011-2012.

MAN, Ronen. La microhistoria como referente teórico-metodológico. Un recorrido por sus vertientes y debates conceptuales. Historia Actual Online, n. 30, p. 167-173, 2013.

MELO, Egle Roberto Menezes de. O coronelismo francano: a consolidação da hegemonia (1880-1914). Franca:UNESP, 1995 (Dissertação de Mestrado em História da UNESP).

MÖRNER, Magnus. The Spanish American hacienda: a survey of recent research and debate. The Hispanic American Historical Review (HAHR), v. 53, n. 2, p. 183-216, 1973.

MÖRNER, Magnus. A economia e a sociedade rural da América do Sul espanhola no período colonial. In: BETHELL, Leslie (org.). História da América Latina: a América Latina colonial.V. II. São Paulo: EDUSP/Fundação Alexandre de Gusmão, 1999, p. 187-217.

MOUTOUKIAS, Zacarías. Las formas complejas de la acción política: justicia corporativa, faccionalismo y redes sociales, Buenos Aires, 1750-1760. Anuario de Historia de América Latina (AHAL), v. 39, p. 69-103, 2002. 
NALDI, Mildred Regina Gonçalves. Coronelismo e poder local. Franca, 1850-1889. Franca: UNESP/Prefeitura Municipal, 1992.

NASCIMENTO, Hygino Andrade do; MOREIRA, Eufrausino. Almanaque histórico de Franca. Franca: Departamento de Imprensa e Propaganda, 1943.

OLIVEIRA, Lélio Luiz de. Heranças guardadas e transições ponderadas: história econômica do interior paulista 1890-1920. Franca: UNESP/FACEF-UNI, 2006.

PALACIOS, Marco. El café en Colombia, 1850-1970: una historia económica, social y política. México: El Colegio de México, 2009.

SÁNCHEZ SANTIRÓ, Ernest. Las incertidumbres del cambio: redes sociales y mercantiles de los hacendados-comerciantes azucareros del centro de México (18001834). IEHS, n. 15, p. 919-968, 2000.

SOUZA, Márcio Luís de. Vida urbana e suburbana nas terras do café: racionalização dos negócios e da vivência coletiva em Ribeirão Preto (1874-1914). Franca: UNESP, 2009 (Dissertação de Mestrado em História da UNESP).

TOSI, Pedro Geraldo. Capitais no interior: Franca e a história da indústria coureiro-calçadista (1860-1945). Franca: FHDSS-UNESP, 2003.

TOSI, Pedro; FALEIROS, Rogério Naques. Domínios do café: ferrovias, exportação e mercado interno em São Paulo (1888-1917). Economia e Sociedade, v. 20, n. 2 (42), p. 417-442, 2011.

VALDERRAMA, Ernesto. Real de Minas de Bucaramanga. 1547-1945. Bucaramanga: Imprenta del Departamento, 1948.

VANYOUNG, Eric. La ciudad y el campo en el México del siglo XVIII. La economía rural de la región de Guadalajara, 1675-1820. México: FCE, 1989.

VER GARA Y VELASCO, Francisco. Nueva geografía de Colombia. Escrita por regiones naturales, 1901. Tomos I, II. Bogotá: Banco de la República/Archivo de la Economía Nacional, 1974.

ZÚÑIGA, Jean-Paul. Clan, parentela, familia, individuo: ¿Qué método y qué niveles de análisis?. Anuario IEHS, n. 15, p. 51-60, 2000. 